\title{
Tissue-Specific Profile of DNA Replication in the Swimming Larvae of Ciona intestinalis
}

\author{
Akie Nakayama, Nori Satoh and Yasunori Sasakura* \\ Department of Zoology, Graduate School of Science, Kyoto University, \\ Sakyo-ku, Kyoto 606-8502, Japan
}

\begin{abstract}
The cell cycle is strictly regulated during development and its regulation is essential for organ formation and developmental timing. Here we observed the pattern of DNA replication in swimming larvae of an ascidian, Ciona intestinalis. Usually, Ciona swimming larvae obtain competence for metamorphosis at about 4-5 $\mathrm{h}$ after hatching, and these competent larvae initiate metamorphosis soon after they adhere to substrate with their papillae. In these larvae, three major tissues (epidermis, endoderm and mesenchyme) showed extensive DNA replication with distinct pattern and timing, suggesting tissue-specific cell cycle regulation. However, DNA replication did not continue in aged larvae which kept swimming for several days, suggesting that the cell cycle is arrested in these larvae at a certain time to prevent further growth of adult organ rudiments until the initiation of metamorphosis. Inhibition of the cell cycle by aphidicolin during the larval stage affects only the speed of metamorphosis, and not the formation of adult organ rudiments or the timing of the initiation of metamorphosis. However, after the completion of tail resorption, DNA replication is necessary for further metamorphic events. Our data showed that DNA synthesis in the larval trunk is not directly associated with the organization of adult organs, but it contributes to the speed of metamorphosis after settlement.
\end{abstract}

Key words: Ascidian, Ciona intestinalis, larvae, DNA replication, aphidicolin, metamorphosis

\section{INTRODUCTION}

Most ascidians perform the dramatic event, metamorphosis, which converts the tadpole-like, mobile larvae into the sessile, filter-feeding adults (Cloney, 1982; Satoh, 1994; Jeffery and Swalla, 1997). Swimming larvae stick on a substrate with adhesive papillae, which triggers sequential events of metamorphosis. The metamorphic events are divided by Cloney (1982) into 10 elements, including tail resorption, rotation of body axis, and development of adult organs from rudiments preexisting in the larval trunk. Ascidian metamorphosis contains many interesting subjects for investigation such as cellular changes, morphogenesis, coordination of the timing of each event, and the genetic pathway conducting metamorphosis.

Recent studies have focused on molecular mechanisms of the initiation of ascidian metamorphosis. In Ciona intestinalis, apoptosis induced by MAPK signaling has a critical role in the initiation of metamorphosis, because the inhibition of apoptosis and MAPK signaling decreases the efficiency of the initiation of metamorphosis (Chambon et al.,

\footnotetext{
* Corresponding author. Phone: +81-75-753-4102; Fax : +81-75-705-1113; E-mail : sasakura@ascidian.zool.kyoto-u.ac.jp
}

2002). In Herdmania curvata, Hemps, an EGF-like signaling molecule, has an inductive role in metamorphosis (Eri et al., 1999). Genes encoding EGF-like molecules are also expressed during metamorphosis of other ascidians such as Ciona intestinalis (Nakayama et al., 2001) and Boltenia villosa (Davidson and Swalla, 2001), suggesting that the EGF signaling has a conserved role in ascidian metamorphosis. In addition, many genes are expressed with possible functions in metamorphosis, although studies should be conducted to reveal the mechanisms by which these genes regulate the complicated metamorphic events (Nakayama et al., 2001; Davidson and Swalla, 2002; Nakayama et al., 2002; Davidson et al., 2003; Woods et al., 2004).

During ascidian development, adult organ rudiment formation starts at the swimming larval stage. In Ciona intestinalis, rudiments of the endostyle, intestine, oral and atrial siphons become visible in the trunk region at 4-9 h after hatching (Chiba et al., 2004), and in some other species such as Distaplia occidentalis, the pharyngeal gill also develops in the larval trunk, and the trunk looks like a miniature of a juvenile (Cloney and Torrence, 1984). The mechanisms of the formation of these adult organ rudiments remain unclear. For example, the pattern of cell division for rudiment formation is not known. In solitary ascidians includ- 
ing Ciona intestinalis, the adult organ rudiments do not grow further in larvae even when they fail to start metamorphosis for more than five days under our culture condition. However, once metamorphosis is initiated, the adult organ rudiments restart their growth and develop rapidly after the completion of tail resorption. The endostyle, pharyngeal gills and intestine become clearly visible within two days after the initiation of metamorphosis, and the structure of the young juvenile with feeding ability is formed. There may be an unknown mechanism which arrests the development of adult organ rudiments until the completion of tail resorption. One possible mechanism may be the regulation of cell division in the adult organ rudiments.

Taking this into consideration, the pattern of cell division in the larval trunk and during metamorphosis should be studied. Recently, Tarallo and Sordion (2004) investigated apoptosis and cell proliferation before and after metamorphosis in Ciona intestinalis. They showed that many tissues are subjected to the combination of apoptosis and cell proliferation, which may result in the formation of proper adult organs. They observed proliferation at two stages of swimming larvae, but some tissues such as epidermis are not described.

To investigate cell cycle regulation at the swimming larval stage and the mechanism of formation of adult organ rudiments, we looked at the pattern of DNA synthesis in the swimming larvae of Ciona intestinalis. We used the incorporation of 5-bromodeoxyuridine (BrdU) and detection of it by its specific antibody to visualize the cells under going $S$ phase (Ganot and Thompson, 2002). We found that the timing of DNA synthesis is strictly regulated among tissues of the larva. By utilizing a chemical to arrest DNA synthesis, aphidicolin (Ikegami et al., 1978), the requirement of cell proliferation for adult organ formation and metamorphic events was also investigated.

\section{MATERIALS AND METHODS}

\section{BrdU incorporation and immunodetection}

BrdU treatment and immunodetection were performed as described by Ganot and Thompson (2002). The concentration of BrdU was $100 \mu \mathrm{M}$. Larvae were incubated in seawater with BrdU for $30 \mathrm{~min}$ at around $19^{\circ} \mathrm{C}$, and then they were fixed with $3.7 \%$ formaldehyde in seawater for $15 \mathrm{~min}$ at room temperature (RT) or overnight at $4^{\circ} \mathrm{C}$. After fixation, specimens were washed twice with PBST $(0.1 \%$ Tween 20 in PBS), and incubated in $5 \mu \mathrm{g} / \mathrm{ml}$ proteinase $\mathrm{K}$ in PBST for 3-6 min at RT. After washing once with PBST, specimens were incubated in $4 \mathrm{M} \mathrm{HCl}$ for $20 \mathrm{~min}$ at $\mathrm{RT}$, then washed twice with PBST, and twice with $0.1 \%$ bovine serum albumin (BSA) in PBST. Specimens were incubated in $5 \%$ fetal bovine serum (FBS) in PBST for $45 \mathrm{~min}$ at RT to block the non-specific binding of antibody, and they were incubated in 1/50 anti-BrdU-Antibody (Roche) in $5 \%$ FBS/PBST for over $16 \mathrm{~h}$ at $4{ }^{\circ} \mathrm{C}$. After washing for over $1 \mathrm{~h}$ with PBST, specimens were incubated in $1 / 100$ AlexaFluor 488 goat anti-mouse IgG (Molecular Probes) in PBST overnight at $4^{\circ} \mathrm{C}$. After washing for over $1 \mathrm{~h}$ with PBST, specimens were mounted with $80 \%$ glycerol $/ 0.5 \% \mathrm{~N}$-propyl-gallate, and were observed with fluorescence microscopy (Zeiss Axiophot2) and confocal microscopy (Zeiss LSM510).

\section{Treatment with aphidicolin}

Animals at the appropriate developmental stages were incubated with aphidicolin (Sigma) at the concentration of $2 \mu \mathrm{g} / \mathrm{ml}$. For negative controls of $\mathrm{BrdU}$ incorporation, larvae pretreated with aphidicolin for $1 \mathrm{~h}$ were incubated in seawater containing BrdU and aphidicolin for $30 \mathrm{~min}$, and fixed to stain BrdU-incorporated cells as described above. To count metamorphosed larvae in aphidicolin, about 20, 30 and 60 larvae were divided just after hatching into each well of a 6 -well plate, and were incubated at $18^{\circ} \mathrm{C}$. These animals were fixed at appropriate timings $[0,3,6,9$ and $12 \mathrm{~h}$ post hatch (hph)] to count the number of animals performing metamorphosis. Larvae performing tail resorption were counted as 'metamorphosed'. To inhibit DNA replication specifically during the larval stage, larvae were treated with aphidicolin at $0 \mathrm{hph}$. The aphidicolin was washed away by changing seawater several times at $9 \mathrm{hph}$ and only metamorphosing larvae remained in the petri dishes. At 33 $\mathrm{hph}$, juveniles were fixed and photographed to observe and measure the length of the endostyle.

Larvae at $0 \mathrm{hph}$ were subjected to seawater containing $0.04 \%$ of colchicine (Sigma) for $8 \mathrm{~h}$ at $18-19^{\circ} \mathrm{C}$, and were fixed by $3.7 \%$ formaldehyde. After washing with PBST, nuclei of the larvae were stained with DAPI $(200 \mu \mathrm{g} / \mathrm{ml})$ in PBST to observe mitotic cells.

\section{RESULTS}

\section{Patterns of DNA replication in swimming larvae}

First, to confirm that BrdU incorporation actually monitors the $S$ phase of the cell division cycle, larvae were pretreated with a DNA replication inhibitor, aphidicolin, and then were incubated in seawater containing BrdU. As shown in Fig. 1A, no signal was observed in aphidicolin-treated larvae, indicating that BrdU specifically labels cells in the $S$ phase. Then, to investigate how cell proliferation is regulated during the larval stage, when the rudiments of adult organs such as the endostyle and the intestine are formed, we observed the patterns of cell proliferation by labeling the proliferating cells with BrdU. Just before hatching [18 h post fertilization (hpf) at $19^{\circ} \mathrm{C}$ ] larvae were subjected to BrdU at 30 min intervals. The temporal change of BrdU incorporation in the epidermis, endoderm and mesenchyme is summarized by a schematic illustration in Fig. 2.

\section{Epidermis}

The epidermis showed the most dramatic changes in $S$ phase during the larval stage (Figs. 2 and 3). Larvae just before hatching did not show DNA synthesis in the epidermis (Fig. 3A). This arrest in epidermis persisted for about 3$4 \mathrm{~h}$ (Fig. 3B-D). The only structures close to the epidermis with BrdU incorporation were the placodes of the oral and atrial siphons (Fig. 3B), but we could not determine whether these were epidermal, mesodermal or endodermal cells. At 3-4 h post hatch ( $\mathrm{hph}$ ), only a few epidermal cells showed BrdU incorporation. This arrest changed after 4-5 hph, when larvae started to obtain competence for metamorphosis (Ishikawa et al., 1972; Jackson and Strathmann, 1981). Larvae of $4-5$ hph showed strong incorporation of BrdU in the trunk epidermis (Fig. 3E). Extensive DNA synthesis in the epidermis continued for 7-8 hph and then decreased gradually (Fig. 3F, G). When tail resorption starts, part of the 
A

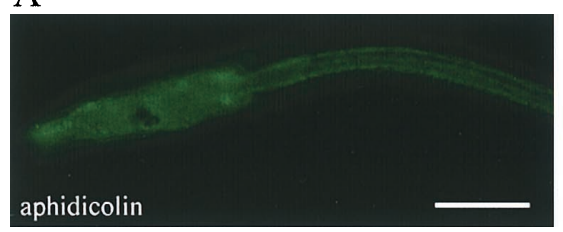

B

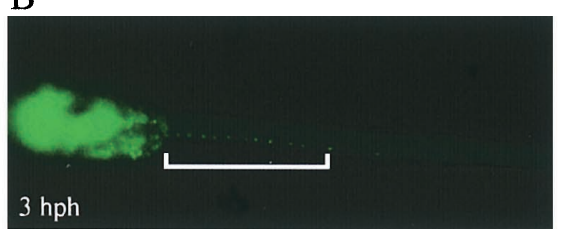

$\mathrm{C}$

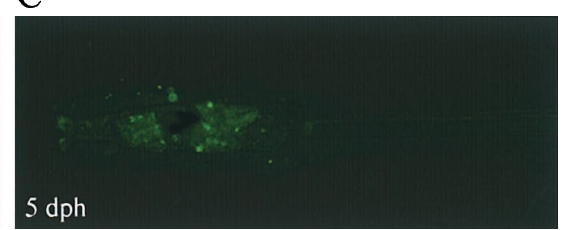

Fig. 1. BrdU staining in larvae. (A) An aphidicolin-treated larva did not show signal in nuclei. Scale bar, $100 \mu \mathrm{m}$. (B) A 3 hph larva showing incorporation of BrdU in the endodermal strand (bracket). (C) An aged larva showed signal in only a few cells in the trunk.
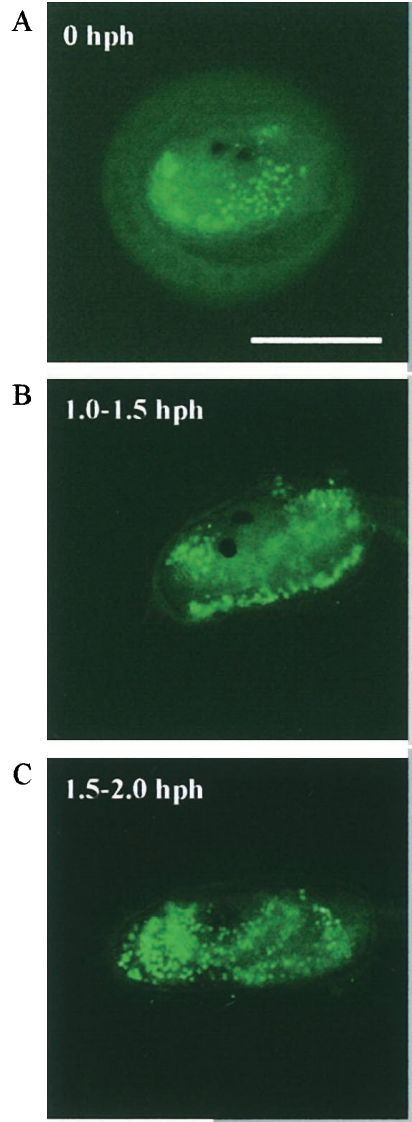

D $3.0-3.5 \mathrm{hph}$

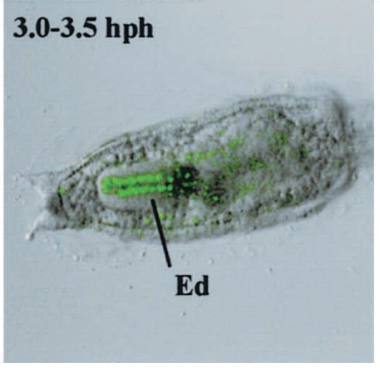

E



F

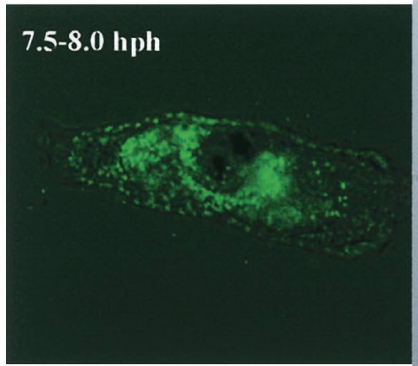

G metamorphosing

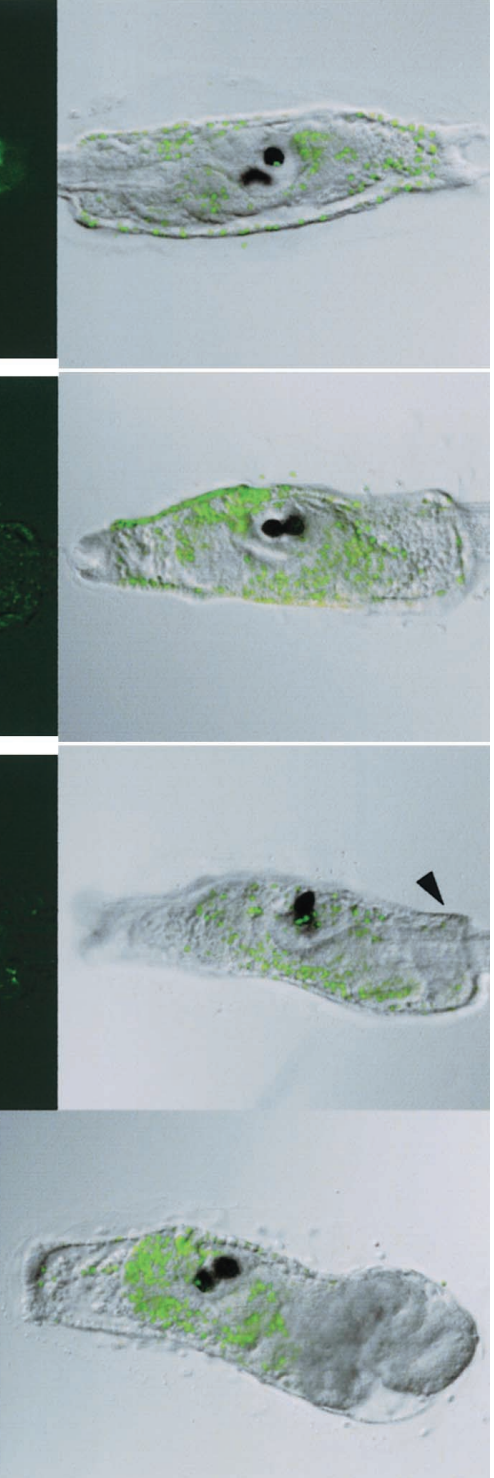

Fig. 3. BrdU incorporation in the trunk of Ciona intestinalis larvae. Photographs with dark field were taken with fluorescent microscopy, and those with bright field were taken with confocal microscopy. (A) Larvae treated with BrdU for 30 min before hatching. Global incorporation of BrdU was observed. Scale bar, $100 \mu \mathrm{m}$. (B) Larvae treated with BrdU for 1.0-1.5 hph. Clear signals were observed in the rudiments of the oral $(\mathrm{Or})$ and atrial (At) siphon. The position of the mesodermal pocket (MP) is shown. (C) Larvae treated with BrdU for 1.5-2.0 hph. Signals were observed in the endostyle disc (Ed) and intestine disc (Int). Mesenchymal cells at the preoral lobe showed strong BrdU incorporation (arrow). (D) Larvae treated with BrdU for 3.0-3.5 hph, ventral view. Only the most interior layer of the endostyle disc that is U-shaped showed staining. (E) Larvae treated with BrdU for 5.0-5.5 hph. Signals were observed in the trunk epidermis. (F) Larvae treated with BrdU for 7.0-7.5 hph. (G) Larvae treated with BrdU for 30 min during tail resorption. The epidermis at the junction between the trunk and tail (arrowhead), that forms the sac for the retracted tail, did not show a signal. (H) Larvae treated with BrdU for 30 min after tail resorption. 


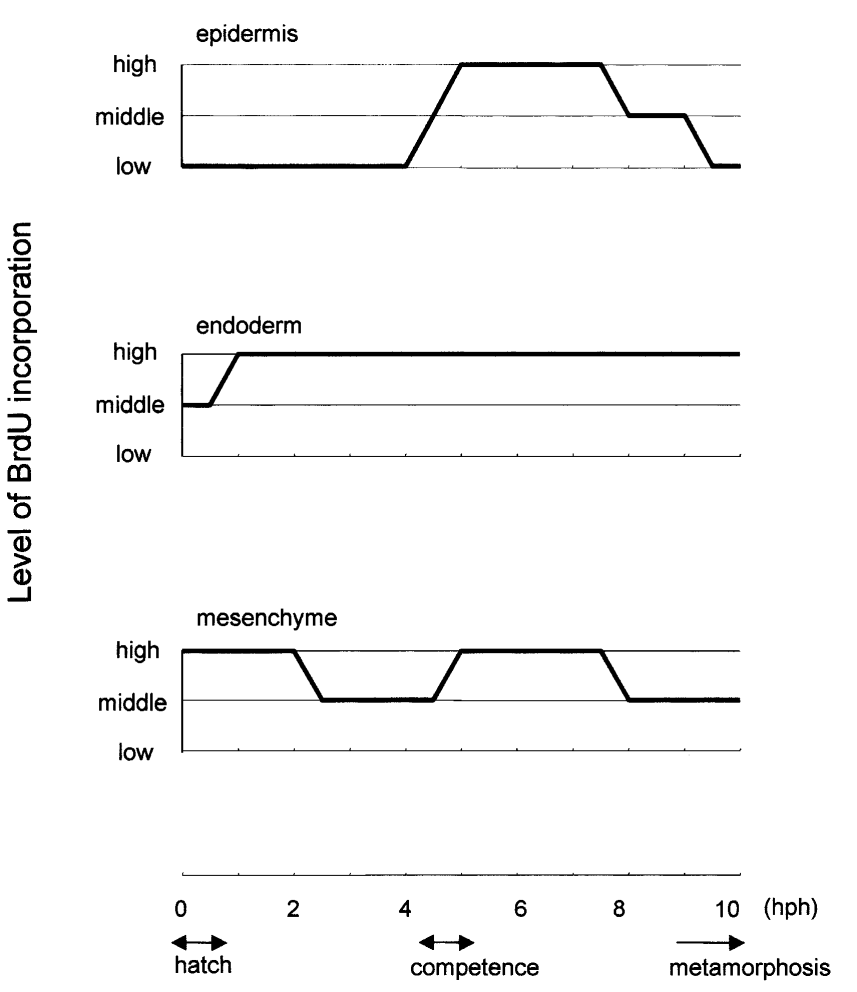

Fig. 2. A schematic illustration showing the temporal change of BrdU incorporation in the epidermis, endoderm and mesenchyme. This illustration does not reflect precise quantitative differences in the amount of BrdU incorporation among these tissues.

epidermis located at the junction between the trunk and tail forms a sac to cover the regressing tail. There seemed to be no BrdU-positive cells in the epidermis of the sac region (Fig. 3G). The juveniles which had finished the tail resorption had only a few epidermal cells with BrdU incorporation (Fig. 3H).

\section{Endoderm}

The endoderm showed the most extensive and continuous incorporation of BrdU (Figs. 2 and 3). Before hatching, the vast region of the endoderm showed strong signals of BrdU incorporation (Fig. 3A). Soon after hatching, DNA synthesis in endodermal cells was not evident (Fig. 3B). After $1.5 \mathrm{hph}$, the anterior region of the endoderm, which gives rise to the endostyle disc, became thick, and this region showed strong BrdU incorporation (Fig. 3C). The ventroposterior region, which gives rise to the intestine disc, and endodermal cells located on the ventral side, also showed weaker but consistent BrdU incorporation. The extensive DNA synthesis at the endostyle disc persisted for about $2 \mathrm{~h}$, while DNA synthesis at the intestine disc decreased. In the endostyle disc, only the most internal layer of cells showed DNA synthesis, when viewed from the ventral side (Fig. 3D). After 4-5 hph, when the epidermal cells started DNA synthesis, the majority of endodermal cells restarted extensive DNA synthesis (Fig. 3E). The extensive DNA synthesis in the intestine disc decreased, while DNA synthesis in the endostyle disc persisted until metamorphosis (Fig. 3F-H).

\section{Mesoderm}

At 0 hph, mesenchymal cells showed strong BrdU incorporation (Figs. 2 and $3 \mathrm{~A}$ ). Soon after hatching, DNA synthesis was restricted to the ventral region and mesodermal pocket (Fig. 3B). After $1.5 \mathrm{hph}$, mesenchymal cells at the preoral lobe increased in number and showed strong BrdU incorporation (Fig. 3C). During the following $3 \mathrm{~h}$, only a portion of cells at the preoral lobe and mesodermal pocket showed DNA synthesis. Around the time when DNA synthesis started in the epidermis, DNA synthesis in the mesenchyme also increased (Figs. 2 and $3 \mathrm{E}$ ). This extensive DNA synthesis continued for about $3 \mathrm{~h}$, after which a proportion of cells in the preoral lobe and mesodermal pocket showed $\mathrm{BrdU}$ incorporation both before and during metamorphosis (Fig. 3F-H).

\section{Other tissues}

We found that only a few cells showed occasional DNA synthesis in the sensory vesicle (Fig. 3A-H). Since Tarallo and Sordino (2004) described DNA replication in cells of the nervous system, we did not perform detailed analyses on other neural cells in the trunk.

Cells in the tail did not show BrdU incorporation. The exception was the cells of the endodermal strand (Fig. 1B), as reported previously (Tarallo and Sordino, 2004). DNA synthesis in the endodermal strand was observed in some, but not all, larvae at 2-5 hph.

\section{DNA replication in the aged larvae}

When cultured in petri dishes, many larvae showed rapid metamorphosis soon after they obtained competence. However, in the ocean, such rapid metamorphosis may not always occur, since larvae probably have to swim for a long distance to find a place to which to adhere. In order to know how the cell cycle is regulated in such aged larvae, $5 \mathrm{dph}$ (days post hatch) larvae which did not start metamorphosis in petri dishes were subjected to BrdU treatment. In these aged larvae, the incorporation of BrdU was very rare (Fig. $1 C)$, suggesting that during the larval stage the $S$ phase is completed by a certain time, and after that the cell cycle may be arrested.

DNA replication during the larval stage is required for the faster completion of body axis rotation, but it is not essential for the patterning of the adult body

The timing of developmental events such as gene expression is strictly regulated during the early development of ascidians (e. g. Fujiwara et al., 2002; Imai et al., 2004). DNA replication is one event responsible for such regulation in ascidians (Satoh and Ikegami, 1981a, b; Satoh, 1982). In order to verify whether DNA replication regulates the timing of events during metamorphosis of larvae, larvae were treated with aphidicolin, and its effect on the adult organ formation and metamorphosis was observed. We chose aphidicolin as the chemical to arrest the cell cycle, since other chemicals used in ascidians such as nocodazole, colchicine 
A
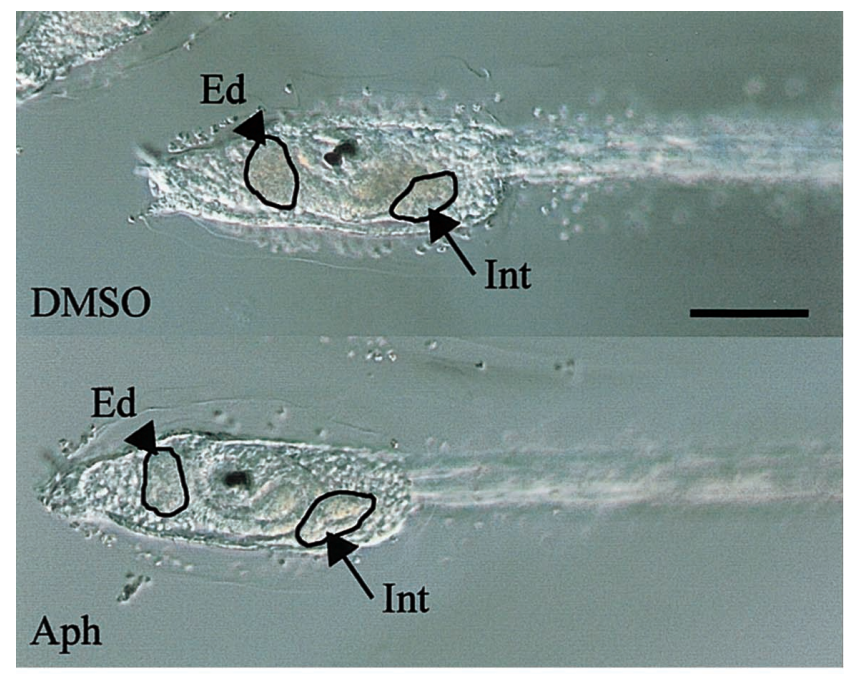

$\mathrm{D}$

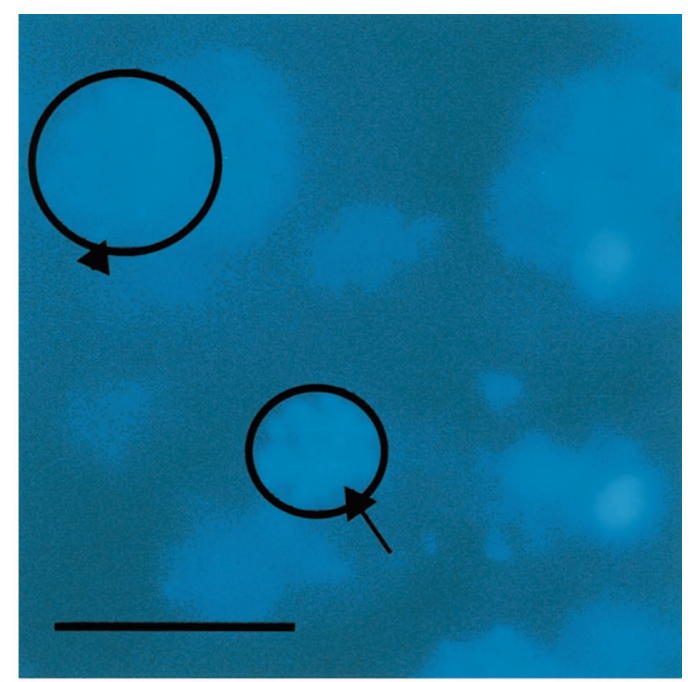

B
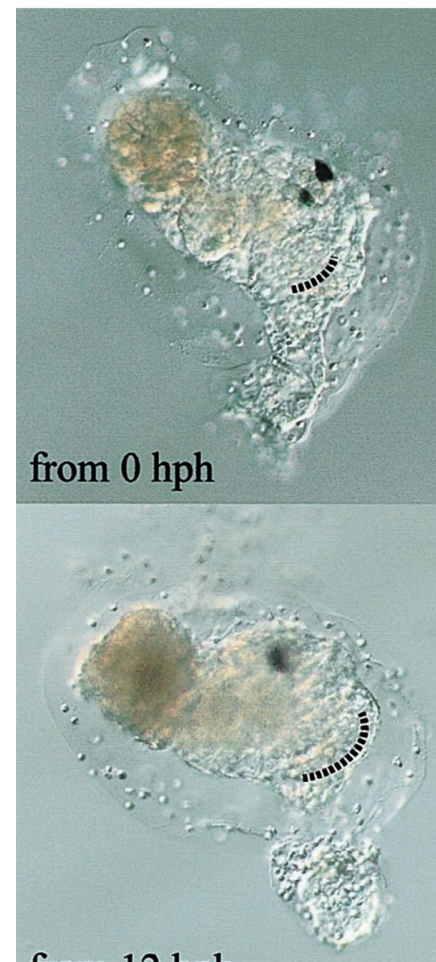

from $12 \mathrm{hph}$

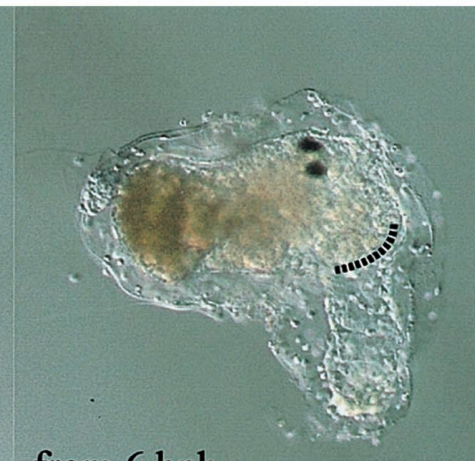

from $6 \mathrm{hph}$



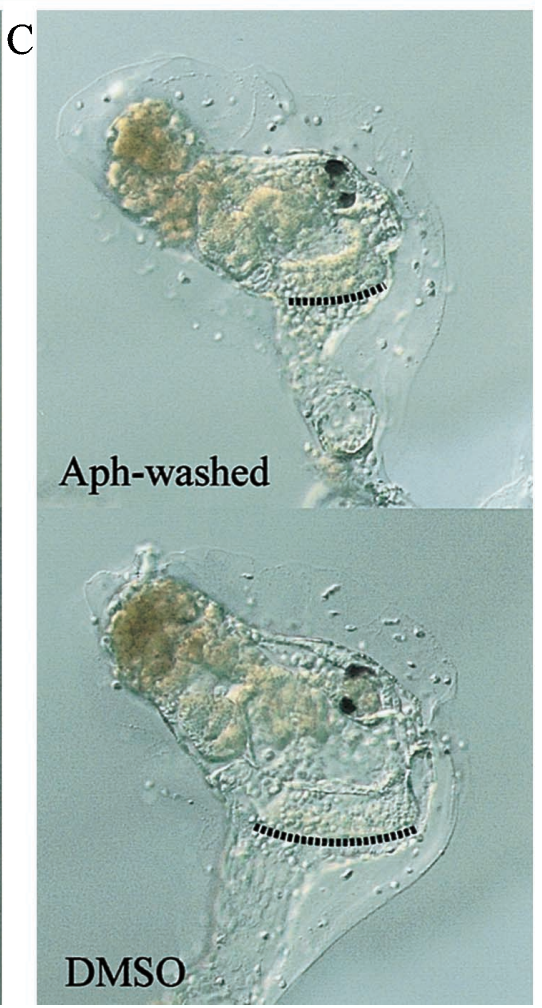

Fig. 4. Effects of aphidicolin on adult organ formation and metamorphosis. (A) An aphidicolin-treated larva (Aph) had an endostyle disc (Ed) and developed an intestine disc (Int). DMSO, a control larva treated with DMSO. Scale bar, $100 \mu \mathrm{m}$ for (A-C). (B) Aphidicolin-treatment from a certain larval stage until the completion of metamorphosis affected body axis rotation and adult organ formation. Animals treated from 0 hph started but did not complete body axis rotation. They had a very small endostyle (dotted lines). The length of the endostyle and the degree of body axis rotation was partially rescued when DNA replication during the larval stage was allowed (from 6 or12 hph). However, these aphidicolin-treated juveniles still had a smaller endostyle and immature adult organs compared with control juveniles (DMSO). (C) A juvenile whose DNA replication was inhibited during the larval stage had a smaller endostyle and slower completion of body axis rotation at one day post hatch. (D) Chromosomes observed in the larval trunk treated with colchicine (arrow). A nucleus at interphase is shown by an arrowhead. Scale bar, $20 \mu \mathrm{m}$.

and cytochalasin B affect not only the cell cycle but also the cytoskeleton. The effect of cytochalasin B on metamorphosis was described in Lash et al. (1973).

At 4-9 hph, rudiments of the intestine and endostyle become clearly visible (Chiba et al., 2004). We observed lar- vae which were treated with aphidicolin for $6 \mathrm{~h}$ from $0 \mathrm{hph}$. Intestine and endostyle discs were formed in these larvae (Fig. 4A), suggesting that DNA replication and subsequent mitosis are not necessary for the formation of these discs. Furthermore, larvae under the aphidicolin treatment during 
the larval stage completed early events of metamorphosis including adhesion to substratum, retraction of adhesive organs and tail resorption (Fig. 4B, 0 hph). The timing of the initiation of metamorphosis was also the same as that of control larvae (Fig. 5A). Therefore, the early events of metamorphosis appear to be independent of DNA replication. Aphidicolin-treated and metamorphosed larvae started rotation of the body axis (Fig. 4B, from 0 hph). However, these larvae did not complete the body axis rotation and their endostyle did not extend, suggesting that the body axis rotation and development of the endostyle require cell division.

To analyze the role of DNA replication during the larval stage, we examined larvae in which the timing of aphidicolin treatment was changed. Aphidicolin treatment was started at several time points after hatching and the treatment was continued until the completion of metamorphosis The effect of the treatment on the organization of body structure of juveniles was observed. When aphidicolin was added from $0 \mathrm{hph}$, the body size of resultant juveniles was much smaller than DMSO-treated controls (Fig. 4B). The endostyle remained as a tiny disc, and the axis rotation was not evident. When aphidicolin treatment was performed from 6 hph, the body size and the size of the endostyle were less affected, and animals treated with aphidicolin from $12 \mathrm{hph}$ developed more normally (Fig. 4B). However, these aphidicolin-treated juveniles did not show perfect organization of juvenile organs. Their endostyles were smaller than controls, and they did not have a beating heart or gill slit opening, indicating that metamorphic events which take place at stage 3b (Chiba et al., 2004) were affected. These data suggest that DNA synthesis in swimming larvae is not directly associated with the completion of body axis rotation and the subsequent development of adult organs, although DNA replication at this stage has a contribution in the development of organs such as the endostyle. Rather, DNA replication and mitosis after the initiation of metamorphosis play critical roles in the completion of metamorphic events such as body axis rotation.

Next, to examine the requirement of DNA replication during the larval stage, larvae just before hatching were treated with aphidicolin. In this experiment, DNA replication was resumed by washing aphidicolin away when larvae started metamorphosis, and these animals were cultured one more day to observe the effect of this treatment. These experimental animals showed slower rotation of body axis and slower development of the endostyle than controls (Figs. 4C and 5B). However, these juveniles showed rapid recovery from the delay, and they became indistinguishable from control juveniles by 2 dph (data not shown). The formation of adult organs such as the intestine, beating heart and pharyngeal gill was normal. Therefore, during the larval stage the $\mathrm{S}$ phase may be required for the faster completion of body axis rotation, but the delay can be recoverable. In addition, the arrest of the cell cycle in the larval trunk does not affect adult organ formation.

DNA replication is required for the expression of tissue- specific markers during early ascidian embryogenesis (Satoh and lkegami, 1981a, b; Satoh, 1982). Taking this into consideration, we examined the possibility that the arrest of DNA replication during the larval stage affects the timing of gene expression. In a previous study, we generated one enhancer-trap line of Ciona intestinalis by Minos-based stable transgenic technique (Sasakura et al., 2003a, b ; Awazu et al., 2004; Matsuoka et al., 2004). This line (Mi[CiTPOgfp]2) entrapped an enhancer of Ci-Musashi, in which GFP is expressed in several organs including the endostyle disc and endostyle after metamorphosis (Awazu et al., 2004). By utilizing this transgenic line, we observed GFP expression in larvae treated with aphidicolin. Both aphidicolin- and DMSO-treated swimming larvae started GFP expression in the endostyle disc at 7-8 hph (data not shown), suggesting that the timing of gene expression in the endostyle seems to be independent of DNA replication.

During this experiment, we found that larvae treated with aphidicolin for a long time were more likely to undergo metamorphosis (Table 1 and Fig. 5A). Because we could not ignore the possibility that aphidicolin affects several cel-

A
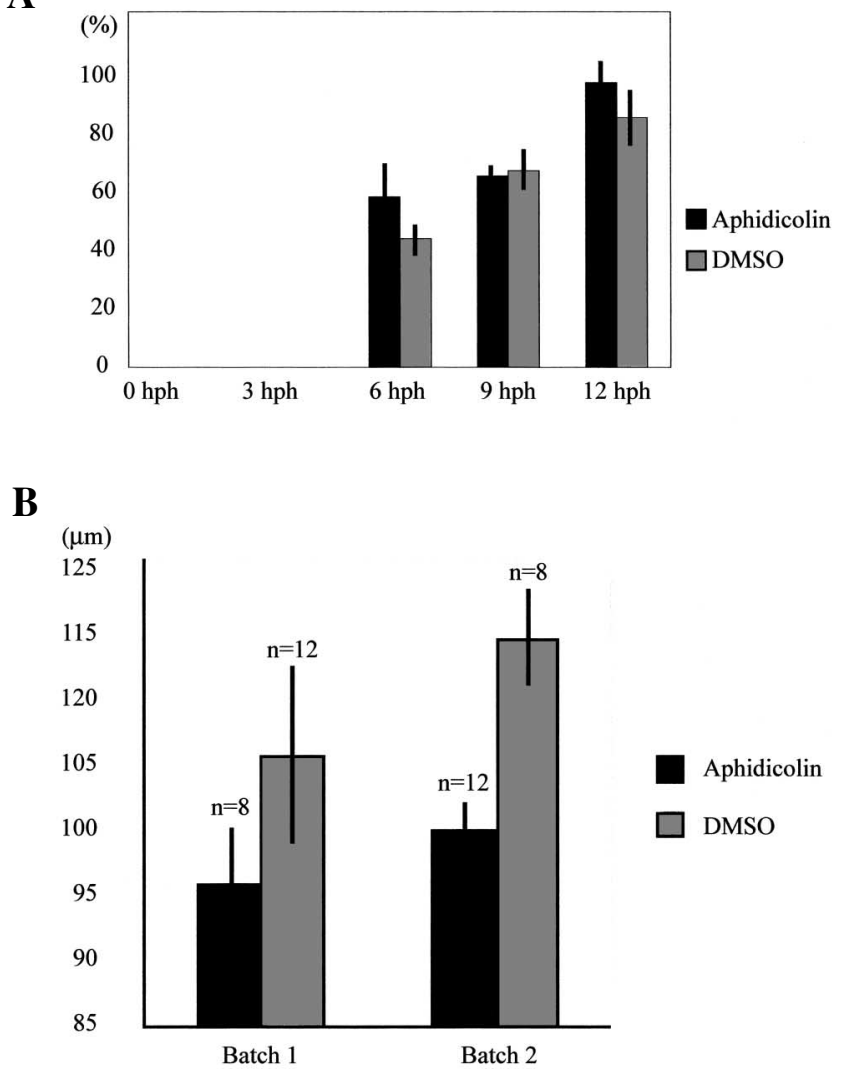

Fig. 5. (A) Aphidicolin-treated larvae showed the normal timing of metamorphosis. The average of the results of 12 experiments is shown. The percentage of larvae starting metamorphosis at each time is shown. At 0 and $3 \mathrm{hph}$, no larva started metamorphosis since larvae did not obtain competence for metamorphosis. (B) Animals in which DNA replication was prevented during the larval stage had a smaller endostyle. Results from two batches are shown. 
Table 1. Effect of aphidicolin treatment on metamorphosis and relationship with MEK inhibitor.

\begin{tabular}{ccc}
\hline Treatment & $\begin{array}{c}\text { No. of larvae } \\
\text { examined }\end{array}$ & $\begin{array}{c}\text { Metamorphosed } \\
\text { larvae (\%) }\end{array}$ \\
\hline DMSO & 432 & 66.8 \\
Aphidicolin & 477 & 85.5 \\
U0126 & 445 & 40.4 \\
Aphidicolin+U0126 & 435 & 64.8 \\
\hline
\end{tabular}

U0126 treatment was started from $13 \mathrm{hpf}\left(18^{\circ} \mathrm{C}\right)$, and aphidicolin treatment was started from $18 \mathrm{hpf}(=0 \mathrm{hph})$. All larvae were fixed at $24 \mathrm{hph}$, and the number of metamorphosed larvae was counted.

lular events other than DNA replication, this result does not necessarily show that suppression of DNA replication induces metamorphosis. The requirement of apoptosis for the initiation of metamorphosis has been shown (Chambon et al., 2002). Observation of apoptosis in aphidicolin-treated larvae by TUNEL staining did not produce a conclusion, since the pattern of TUNEL-positive signals was very different between larvae. Treatment with U0126, an inhibitor of MAP kinase signaling whose repression inhibits metamorphosis (Chambon et al., 2002), reduced the effect of aphidicolin (Table 1).

\section{Cell division in swimming larvae}

The above mentioned results suggest that DNA replication and cell division at the swimming larval stage is not directly associated with adult organ (rudiment) formation even though DNA replication during the larval stage was impaired, and its effect on body axis rotation was small. We suspected that most cells at the $S$ phase in the larval trunk do not perform cell division by the G2 arrest, and because of the arrest, the inhibition of cell cycle by aphidicolin might have little effect. Tarallo and Sordino (2004) observed the phosphorylation of histone $\mathrm{H} 3$ in the larval trunk, the hallmark of mitosis (Cheung et al., 2000; Lim et al., 2004), suggesting that some of the cells may perform mitosis. However, this is not direct evidence of cell division, because phosphorylation of $\mathrm{H} 3$ does not necessarily mean mitosis. To obtain direct evidence of cell division in the larval trunk, we tried to find condensed chromosomes in the larval trunk by staining nuclei with DAPI. To accumulate dividing cells, larvae were subjected to colchicine treatment for over $8 \mathrm{~h}$ from hatching, and they were fixed to stain them with DAPI. In this case, we found many cells having condensed chromosomes (Fig. 4D, arrow), suggesting that cells that finished DNA replication performed mitosis. Even though larvae were treated with colchicine for longer, many cells had interphase nuclei (Fig. 4D). Given that not all cells perform DNA synthesis (Figs. 2 and 3), some cells might be arrested at a specific point in the cell cycle. Or alternatively, DNA synthesis may be started at later timing in some cells and was not completed during the period of observation.

\section{DISCUSSION}

In the present study, we described the pattern of DNA replication in cells of Ciona intestinalis swimming larvae. The timing of DNA replication was regulated in a tissue-specific manner. DNA replication in the larval trunk before the initiation of metamorphosis contributes to the rapid completion of body axis rotation, but is basically dispensable for the formation of adult organ rudiments and for metamorphic events. In contrast, DNA replication after tail resorption is required for the completion of metamorphosis and growth of adult organs. If larvae fail to initiate metamorphosis for a long time, the cell cycle is arrested at a certain point. These findings provide us with the basics of cellular events in swimming larvae preparing for metamorphosis.

The epidermis, endoderm and mesenchyme showed different timings of DNA replication, as summarized in Fig. 2. While DNA replication in epidermal cells was suspended, cells in other tissues performed extensive DNA replication. In addition, not all of the endodermal and mesodermal cells performed DNA replication. The clearest example of a subpopulation in a tissue was the endostyle disc (Fig. 3D). These data suggest a mechanism responsible for differential regulation of the cell cycle in each tissue and subpopulation of cells. And the regulation of the cell cycle may be related to the mechanism which regulates metamorphic events, since the epidermis, endoderm and mesenchymal cells restart extensive DNA replication around the time when swimming larvae acquire the competence for metamorphosis (Fig. 2). DNA replication ceases in aged larvae, suggesting the presence of another mechanism which suspends the cell cycle until the start of metamorphosis. This arrest may be broken when metamorphosis is initiated after settlement. Such regulation may explain the inhibition of the growth of adult organs in larvae of Ciona intestinalis. The development of adult organ rudiments in the larval trunk differs between solitary and colonial ascidians. In colonial ascidians, adult organs are well developed in larvae (Cloney, 1982; Satoh, 1994), while adult organ formation was strongly arrested in larvae of solitary ascidians. This difference in the state of prospective juvenile organs and their rudiments might be caused by the different timing of cell cycle arrest.

We first speculated that DNA replication and subsequent mitosis at the larval stage might be necessary for the formation of adult organ rudiments, but this is not the case. The endostyle disc and intestine disc formed even though DNA replication and subsequent cell division were arrested. Cell division in swimming larvae is not always required for the formation of these adult organ rudiments. Although we did not examine effect of aphidicolin treatment on other rudiments, the overall patterning of the larval trunk may be normal in aphidicolin-treated larvae, because aphidicolin treatment at the larval stage did not affect the formation of adult organs after metamorphosis. Therefore, the number of cells at hatching is sufficient to generate the adult organ rudiments, and they may be formed independently of cell divi- 
sion. In Halocynthia roretzi, the frequency of cell proliferation decreased as embryos developed (Yamada and Nishida, 1999). At the hatching stage, only three percent of cells divide. In addition, embryos from partial egg fragments develop into swimming larvae with normal morphology, while cell number is smaller than in control larvae (Yamada and Nishida, 1999). These data are consistent with our finding that the increase in cell number is not necessary for the patterning of adult organ rudiments in swimming larvae. The cell number in the trunk of the larva is not sufficient to generate the developed adult organs, as suggested by aphidicolin-treatment from 6-12 hph (Fig. 4). With the pulse treatment of aphidicolin by washing it away after the initiation of metamorphosis, the only effect observed was in the speed of completion of the body axis rotation and subsequent organ growth. Therefore, DNA replication at the swimming larva stage may be in preparation for rapid growth of juveniles after tail resorption. Swimming larvae of ascidians cannot take food because the digestive organs are not developed. Therefore, such rapid growth might be necessary for the rapid reconstruction of a body with feeding ability.

Ascidian metamorphosis is a dramatic event during their life cycle. Through this event, they change their swimming, non-feeding larval body into a sessile, filter feeder. How this complicated event is accurately achieved is an interesting question. In the present study, we found celltype-dependent cell cycle regulation in swimming larvae of Ciona intestinalis. This phenomenon provides us with a good example for understanding the mechanism of cell cycle regulation during development. In Ciona intestinalis, the draft genome sequences have been determined (Dehal et al., 2002), a large EST/cDNA database is available (Satou et al., 2002), and many genes including genes regulating the cell cycle are annotated (e. g. Kawashima et al., 2003; Sasakura et al., 2003c, d; Satou and Satoh, 2003). Gene knockdown by morpholino oligonucleotide is effective (Satou et al., 2001; Yamada et al., 2003). Splendid genetic approaches, such as the generation of stable transgenic lines, insertional mutagenesis and enhancer trap screening are possible by Minos transposon (Sasakura et al., 2003a, b; Awazu et al., 2004; Matsuoka et al., 2004). By utilizing these useful information and techniques, the characterization of the mechanism of cell cycle regulation and the mechanism of metamorphosis will be achieved.

\section{ACKNOWLEDGMENTS}

We are grateful to all members of the Maizuru Fishery Research Station of Kyoto University, the International Coastal Research Center of the Ocean Research Institute of the University of Tokyo, Marine Biological Laboratory, Graduate School of Science, University of Hiroshima, and the Education and Research Center of Marine Bio-resources, Tohoku University, for collection of Ciona adults. We thank Dr. Tatsuya Oshika and members of Kobe Municipal Suma Aqualife Park for helping us to obtain seawater. Dr. Yutaka Satou, Ms Kazuko Hirayama and Mr. Yoshikazu Okada are acknowledged for supporting us with experiments and Ciona cultur- ing. YS is a Postdoctoral Fellow of JSPS with a research grant (No. 0200967). AN is supported by a Grant for the Biodiversity Research of the 21 st Century COE (A14).

\section{REFERENCES}

Awazu S, Sasaki A, Matsuoka T, Satoh N, Sasakura Y (2004) An enhancer trap in the ascidian Ciona intestinalis identifies enhancers of its Musashi orthologous gene. Dev Biol 275: 459472

Chambon JP, Soule J, Pomies P, Fort P, Sahuquet A, Alexandre D, Mangeat $\mathrm{PH}$, Baghdiguian S (2002) Tail regression in Ciona intestinalis (Protochordate) involved a Caspase-dependent apoptosis event associated with ERK activation. Development 129: 3105-3114

Cheung P, Allis CD, Sassone-Corsi $\mathrm{P}$ (2000) Signaling to chromatin through histone modifications. Cell 103: 263-271

Chiba S, Sasaki A, Nakayama A, Takamura K, Satoh N (2004) Development of Ciona intestinalis juveniles (through 2nd ascidian stage). Zool Sci 21: 285-298

Cloney RA (1982) Ascidian larvae and the events of metamorphosis. Amer Zool 22: 817-826

Cloney RA, Torrence SA (1984) Ascidian larvae: Structure and settlement In "Biodeterioration," Ed by JD Costlow, US Naval Institute, Annapolis, Maryland, pp 141-148

Corbo JC, Di Gregorio A, Levine M (2001) The ascidian as a model organism in developmental and evolutionary biology. Cell 106: $535-538$

Davidson B, Swalla BJ (2001) Isolation of genes involved in ascidian metamorphosis: epidermal growth factor signaling and metamorphic competence. Dev Genes Evol 211: 191-194

Davidson B, Swalla BJ (2002) A molecular analysis of ascidian metamorphosis reveals activation of an innate immune response. Development 129: 4739-4751

Davidson B, Smith Wallance SE, Howsmon RA, Swalla BJ (2003) A morphological and genetic characterization of metamorphosis in the ascidian Boltenia villosa. Dev Genes Evol 213: 601-611

Dehal P, Satou Y, Campbell RK et al. (2002) The draft genome of Ciona intestinalis: insight into chordate and vertebrate origins. Science 298: 2157-2167

Eri R, Arnold JM, Hinman VF, Green KM, Jones MK, Degnan BM, Lavin MF (1999) Hemps, a novel EGF-like protein, plays a central role in ascidian metamorphosis. Development 126: 58095818

Fujiwara S, Maeda Y, Shin-I T, Kohara Y, Takatori N, Satou Y, Satoh N (2002) Gene expression profiles in Ciona intestinalis cleavage-stage embryos. Mech Dev 112: 115-127

Ganot P, Thompson EM (2002) Patterning through differentiation endoreduplication in epithelial organogenesis of the Chordate, Oikopleura dioica. Dev Biol 252: 59-71

Ikegami S, Taguchi T, Ohashi M, Oguro M, Nagano H, Mano, Y (1978) Aphidicolin prevents mitotic cell division by interfering with activity of DNA polymerase- $\alpha$. Nature 275: 458

Imai KS, Hino K, Yagi K, Satoh N, Satou Y (2004) Gene expression profiles of transcription factors and signaling molecules in the ascidian embryo: towards a comprehensive understanding of gene networks. Development 131: 4047-4058

Ishikawa M, Numakunai T, Vincentiis MD, Lancieri M (1972) Enzymatic activities relating to the respiration and the onset of metamorphosis of the ascidian tadpole. Dev Growth Differ 14: 229 236

Jackson GA, Strathmann RR (1981) Larval mortality from offshore mixing as a link between percompetent and competent period of development. Am Nat 118: 16-25

Jeffery WR, Swalla BJ (1997) Constructing the organism In "Embryology" Ed by S Gilbert, Sinauer, Sunderland, pp 331-364 
Kawashima T, Tokuoka M, Awazu S, Satoh N, Satou Y (2003) A genomewide survey of developmentally relevant genes in Ciona intestinalis VIII Genes for PI3K signaling and cell cycle. Dev Genes Evol 213: 284-290

Lash JW, Cloney RA, Minor RR (1973) The effect of cytochalasin B upon tail resorption and metamorphosis in ten species of ascidians. Biol Bull145: 360-372

Lim JH, Catez F, Birger Y, West KL, Prymakowska-Bosak M, Postnikov YV, Bustin M (2004) Chromosomal Protein HMGN1 Modulates Histone H3 Phosphorylation. Mol Cell 15: 573-584

Matsuoka T, Awazu S, Satoh N, Sasakura Y (2004) Minos transposon causes germline transgenesis of the ascidian Ciona savignyi. Dev Growth Differ 46: 249-255

Nakayama A, Satou Y, Satoh N (2001) Isolation and characterization of genes that are expressed during Ciona intestinalis metamorphosis. Dev Genes Evol 211: 184-189

Nakayama A, Satou Y, Satoh N (2002) Further characterization of genes expressed during Ciona intestinalis metamorphosis. Differentiation 70: 429-437

Sasakura Y, Awazu S, Chiba S, Kano S, Satoh N (2003a) Application of Minos, one of the Tc1/mariner superfamily transposable elements, to ascidian embryos as a tool for insertional mutagenesis. Gene 308: 11-20

Sasakura Y, Awazu S, Chiba S, Satoh N (2003b) Germ-line transgenesis of the Tc1/mariner superfamily transposon Minos in Ciona intestinalis. Proc Natl Acad Sci USA 100: 7726-7730

Sasakura Y, Yamada L, Takatori N, Satou Y, Satoh, N (2003c) A genomewide survey of developmentally relevant genes in Ciona intestinalis VII Molecules involved in the regulation of cell polarity and actin dynamics. Dev Genes Evol 213: 273-283

Sasakura Y, Shoguchi E, Takatori N, Wada S, Meinertzhagen IA, Satou Y, Satoh N (2003d) A genomewide survey of developmentally relevant genes in Ciona intestinalis $X$ Genes for cell junctions and extracellular matrix. Dev Genes Evol 213: 303313

Satoh N (1982) DNA replication is required for tissue-specific enzyme development in ascidian embryos. Differentiation 21: $37-40$
Satoh N (1994) Developmental biology of ascidians, Cambridge Univ Press, New York

Satoh N (2003) The ascidian tadpole larva: comparative molecular development and genomics. Nat Rev Genet 4: 285-295

Satoh N, Ikegami S (1981a) On the 'clock' mechanism determining the time of tissue-specific enzyme development during ascidian embryogenesis II Evidence for association of the clock with the cycle of DNA replication. J Embryol Exp Morphol 64: 61

Satoh N, Ikegami S (1981b) A definite number of aphidicolin-sensitive cell-cycle events are required for acetylcholinesterase development in the presumptive muscle cells of the ascidian embryos. J Embryol Exp Morphol 61: 1

Satou Y, Satoh N (2003) Genomewide surveys of developmentally relevant genes in Ciona intestinalis. Dev Genes Evol 213: 211213

Satou Y, Imai-Satou K, Satoh N (2001) Action of morpholinos in Ciona embryos. Genesis 30: 103-106

Satou Y, Yamada L, Mochizuki Y, Takatori N, Kawashima T, Sasaki A, Hamaguchi M, Awazu S, Yagi K, Sasakura Y, Nakayama A, Ishikawa $\mathrm{H}$, Inaba $\mathrm{K}$, Satoh N (2002) A cDNA resource from the basal chordate Ciona intestinalis. Genesis 33: 153-154

Tarallo R, Sordino P (2004) Time course of programmed cell death in Ciona intestinalis in relation to mitotic activity and MAPK signaling. Dev Dyn 230: 251-262

Woods RG, Roper KE, Gauthier M, Bebell LM, Sung K, Degnan BM, Lavin MF (2004) Gene expression during early ascidian metamorphosis requires signaling by Hemps, an EGF-like protein. Development 131: 2921-2933

Yamada A, Nishida H (1999) Distinct parameters are involved in controlling the number of rounds of cell division in each tissue during ascidian embryogenesis. J Exp Zool 284: 379-391

Yamada L, Shoguchi E, Wada S, Kobayashi K, Mochizuki Y, Satou Y, Satoh N (2003) Morpholino-based gene knockdown screen of novel genes with developmental function in Ciona intestinalis. Development 130: 6485-6495

(Received November 10, 2004 / Accepted December 28, 2004) 